María Eugenia Chamorro*, Romina Maltaneri, Agustina Schiappacasse, Alcira Nesse and Daniela Vittori

\title{
Role of protein tyrosine phosphatase 1B (PTP1B) in the increased sensitivity of endothelial cells to a promigratory effect of erythropoietin in an inflammatory environment
}

https://doi.org/10.1515/hsz-2020-0136

Received February 14, 2020; accepted May 4, 2020; published online July 16,2020

\begin{abstract}
The proliferation and migration of endothelial cells are vascular events of inflammation, a process which can also potentiate the effects of promigratory factors. With the aim of investigating possible modifications in the activity of erythropoietin (Epo) in an inflammatory environment, we found that Epo at a nonpromigratory concentration was capable of stimulating EA.hy926 endothelial cell migration when TNF- $\alpha$ was present. VCAM-1 and ICAM-1 expression, as well as adhesion of monocytic THP-1 cells to endothelial layers were also increased. Structurally modified Epo (carbamylation or $N$-homocysteinylation) did not exhibit these effects. The sensitizing effect of TNF- $\alpha$ on Epo activity was mediated by the Epo receptor. Inhibition assays targeting the PI3K/mTOR/NF- $\mathrm{kB}$ pathway, shared by Epo and TNF- $\alpha$, show a cross-talk between both cytokines. As observed in assays using antioxidants, cell migration elicited by TNF- $\alpha+$ Epo depended on TNF- $\alpha$-generated reactive oxygen species (ROS). ROS-mediated inactivation of protein tyrosine phosphatase 1B (PTP1B),
\end{abstract}

María Eugenia Chamorro and Romina Maltaneri: These authors contributed equally to this work.

\footnotetext{
*Corresponding author: María Eugenia Chamorro, Universidad de Buenos Aires, Consejo Nacional de Investigaciones Científicas y Técnicas, Instituto del Departamento de Química Biológica de la Facultad de Ciencias Exactas y Naturales (IQUIBICEN), Departamento de Química Biológica, Facultad de Ciencias Exactas y Naturales, Ciudad Autónoma de Buenos Aires, C1428EHA, Argentina, e-mail: mechamorro@qb.fcen.uba.ar. https://orcid.org/0000-00034377-0876

Romina Maltaneri, Agustina Schiappacasse, Alcira Nesse and Daniela Vittori: Universidad de Buenos Aires, Consejo Nacional de Investigaciones Científicas y Técnicas, Instituto del Departamento de Química Biológica de la Facultad de Ciencias Exactas y Naturales (IQUIBICEN), Departamento de Química Biológica, Facultad de Ciencias Exactas y Naturales, Ciudad Autónoma de Buenos Aires, C1428EHA, Argentina
}

involved in Epo signaling termination, could explain the synergistic effect of these cytokines. Our results suggest that ROS generated by inflammation inactivate PTP1B, causing the Epo signal to last longer. This mechanism, along with the cross-talk between both cytokines, could explain the sensitizing action of TNF- $\alpha$ on the migratory effect of Epo.

Keywords: cytokine receptors; endothelial cells; erythropoietin; protein tyrosine phosphatase $1 \mathrm{~B}$; reactive oxygen species; tumor necrosis factor $\alpha$.

\section{Introduction}

Erythropoietin (Epo) is the required cytokine for promoting survival, proliferation and differentiation of erythroid progenitor cells through its homodimeric receptor EpoR, thus maintaining the adequate mass of mature erythroid cells. However, erythropoiesis stimulation is not the only function of this hormone. The widespread distribution of EpoR in brain cells, myoblasts, adipocytes, endothelium and other cell types permits the activity of Epo in nonhematopoietic tissues, particularly cell protection against proapoptotic stimuli.

Expression of EpoR in endothelial cells facilitates the promotion of angiogenesis by Epo. This process may contribute to cardioprotection in ischemic injury, a condition characterized by the release of nuclear factor $\kappa B(N F-\kappa B)$, reactive oxygen species (ROS) accumulation and inflammation. In this context, previous studies have shown that Epo increased endothelial cell proliferation and neovascularization (Doleschel et al. 2015; Zhu et al. 2019).

Epo binding induces phosphorylation of Janus kinase 2 (Jak2), thus initiating the activation of downstream signaling pathways such as that of the signal transducer and activator of transcription 5 (STAT5), the extracellular signal-regulated kinase (ERK), and the phosphatidylinositol 3-kinase (PI3K)/ AKT. Since the phosphorylation of protein tyrosyl residues is 
a critical event in many signaling pathways involved in proliferation, differentiation and cellular response to Epo, phosphatases become important factors in the downregulation of such activities. Among these enzymes, the protein tyrosine phosphatase (PTP) family and its prototype PTP1B in particular, have been characterized in the attenuation of Epo signaling (Callero et al. 2007; Myers et al. 2001).

It is well-known that the therapeutical action of recombinant human erythropoietin (rhuEpo) is widely used to counteract anemia, especially in patients with chronic diseases. The fact that these chronic pathologies are strongly associated with inflammation highlights the importance of understanding the activity of Epo in the presence of proinflammatory cytokines. Stemming from this, the aim of the present investigation was to study whether any biological function of the hormone Epo may be modified by an inflammatory environment in endothelial cells. Epo was used at a non-promigratory concentration in an inflammatory environment generated by the presence of tumor necrosis factor alpha (TNF- $\alpha$ ). This model was applied in assays to evaluate the effect of the simultaneous action of both cytokines on endothelial cell migration, expression of adhesion molecules and cell adhesion, and to further elucidate the mechanisms involved.

On the other hand, in candidates to long-term Epo treatment, such as patients with chronic kidney disease (CKD) or chronic heart failure (CHF), increased levels of structurally modified circulating proteins have been reported (Kraus et al. 1998; Sikora et al. 2014), due to their reaction with accumulated metabolic substances associated to the pathology. In renal patients, who routinely receive rhuEpo therapy to overcome anemia, plasma proteins may be carbamylated by the cyanate derived from urea hydrolysis. It is known that carbamylated Epo (cEpo) loses its erythropoietic ability but retains its antiapoptotic capacity (Chamorro et al. 2013; Leist et al. 2004). Hyperhomocysteinemia, frequently found in CHF, is another condition that may cause protein modification, in this case through homocysteinylation. Epo $N$-homocysteinylation by reaction with homocysteine thiolactone (HTL), the highly reactive metabolite of homocysteine, generates oligomeric structures with loss of erythropoietic activity (Schiappacasse et al. 2018). In the light of this evidence, it seemed interesting to study the action of those modified erythropoietins on endothelial cells under an inflammatory environment to compare it with that of the native Epo.

The results of this work will increase the knowledge of Epo behavior on endothelial cells in an inflammatory environment, a state closely associated to anemia of chronic diseases, and are expected to be used in the future to adequate therapeutic protocols.

\section{Results}

\section{Effect of TNF- $\alpha$ and erythropoietin on endothelial cell migration}

Evidence exists of a critical role of TNF- $\alpha$ in tumor proliferation, through endothelial cell migration, invasion and tube formation ( $\mathrm{Wu}$ and Zhou 2010). We previously found a promigratory effect of the inflammatory cytokine in wound healing assays performed in cultures of the human endothelial EA.hy926 cell line. We also demonstrated endothelial cell motility induced by Epo $(200 \mathrm{ng} / \mathrm{ml})$ which increased by coincubation with TNF- $\alpha$ (Maltaneri et al. 2018). With the aim of characterizing the effect of both cytokines on cell migration, in the present work, wound healing and other assays were performed using a substimulatory concentration of Epo $(80 \mathrm{ng} / \mathrm{ml})$. Although no effect of Epo alone was detected at this concentration, the migration of endothelial EA.hy926 cells was significantly enhanced by the simultaneous presence of Epo and TNF- $\alpha$ (Figure 1).

In a similar experiment, we compared the behavior of Epo molecules structurally modified by carbamylation (cEpo) or $N$-homocysteinylation (HTLEpo) with that of the native Epo at the same concentration $(200 \mathrm{ng} / \mathrm{ml})$. In stark contrast with Epo, the carbamylated derivative cEpo was unable to induce cell migration when administered alone, and coincubation with TNF- $\alpha$ failed to enhance its activity either at $80 \mathrm{ng} / \mathrm{ml}$ (data not shown) or a higher concentration (Figure 1). In a similar way, HTLEpo did not exhibit significant activity on cell migration when added to the cultures alone or with the proinflammatory cytokine. Taken together, the results presented in Figure 1 show that structural changes - due to protein carbamylation or $\mathrm{N}$ homocysteinylation - affect the promigratory action of Epo and its synergistic effect with TNF- $\alpha$ on EA.hy926 endothelial cells.

\section{Effect of TNF- $\alpha$ and erythropoietin on cell adhesion}

The vascular inflammatory reaction is mediated by complex interactions between the circulating leukocytes and the vascular wall. Endothelial cells regulate the inflammatory process by means of the expression of adhesion molecules, cytokines, chemokines and growth factors. Various cell adhesion molecules have been identified in 
A

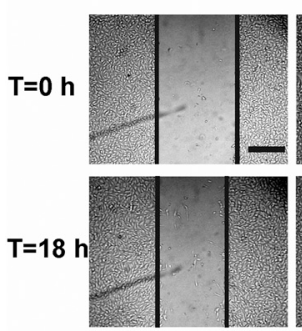

Control
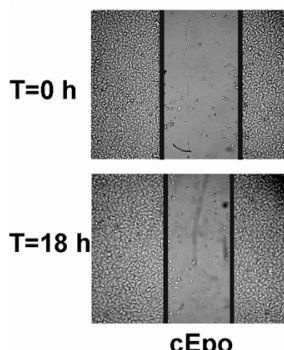

cEpo

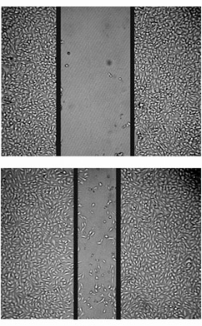

TNF- $\alpha$

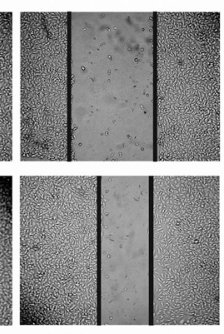

TNF- $\alpha+c E p o$

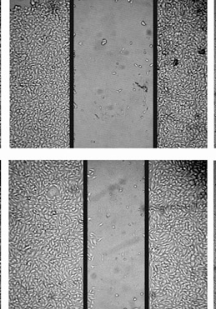

Epo $200 \mathrm{ng} / \mathrm{ml}$
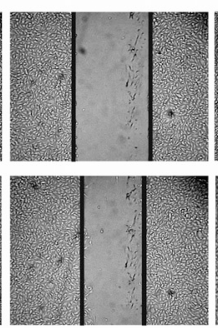

HTLEpo

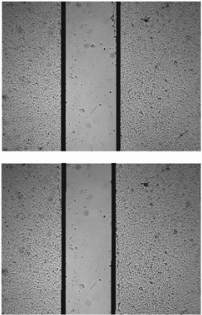

Epo 80ng/ml

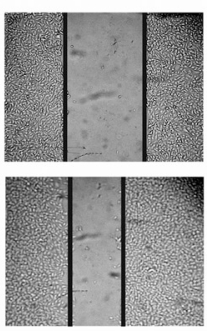

TNF- $\alpha+$ HTLEpo
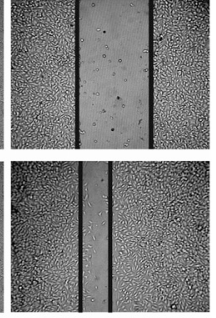

TNF- $\alpha+$ Epo 80
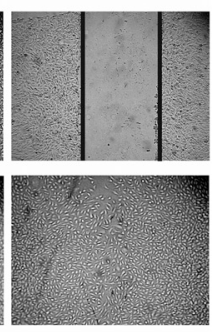

FBS

B

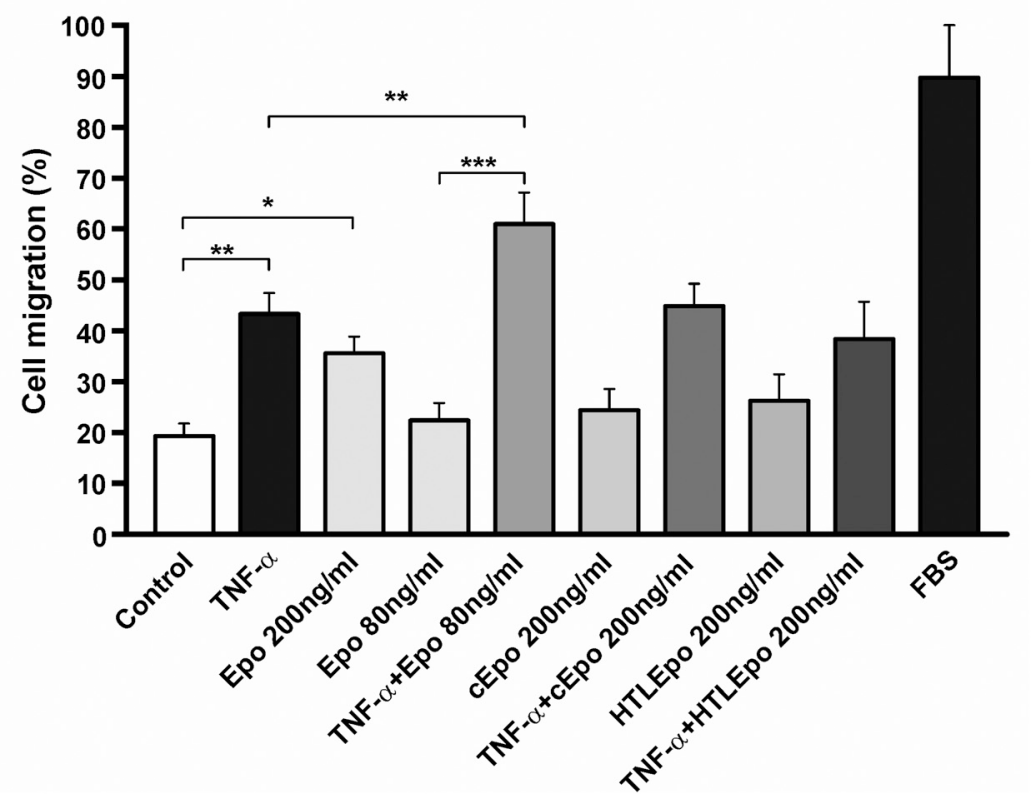

Figure 1: Synergistic effect of TNF- $\alpha$ and Epo on endothelial cell migration. Wound healing assay: After $18 \mathrm{~h}$ of serum starvation ( $t=0$ ), EA.hy926 cells were incubated with Epo ( 80 or $200 \mathrm{ng} / \mathrm{ml})$, cEpo $(200 \mathrm{ng} / \mathrm{ml})$ or HTLEpo $(200 \mathrm{ng} / \mathrm{ml})$ in the presence or absence of TNF- $\alpha(30 \mathrm{ng} / \mathrm{ml})$, followed by wound healing assay. Cell migration was assessed by measuring wound width in photographs taken at $t=0 \mathrm{~h}$ and $t=18 \mathrm{~h}$. Controls consisted of cells cultured without FBS, and with $10 \%$ FBS (promigratory control). (A) Photographs are representative of seven independent assays (Bar: $500 \mu \mathrm{m}$ ). (B) Bars represent Mean \pm SEM. Significant differences: " $P<0.05$; "* $P<0.01$;

${ }^{* * *} P<0.001 ; n=7$. No significant differences were found between $c$ Epo $200 \mathrm{ng} / \mathrm{ml}+$ TNF- $\alpha$ or HTLEpo $200 \mathrm{ng} /$ $\mathrm{ml}+$ TNF- $\alpha$ versus TNF- $\alpha$. endothelial cells, such as the intercellular adhesion molecule 1 (ICAM-1) and the vascular cell adhesion molecule 1 (VCAM-1), which were found upregulated in the vascular endothelium in response to inflammatory stimuli (Kim et al. 2008; Lin et al. 2015). Therefore, we were interested in studying the regulation of adhesion molecules as well as white blood cell adhesion in cultures of EA.hy926 cells exposed to both TNF- $\alpha$ and Epo. Using fluorescence microscopy and fluorometric quantitation, we demonstrated that the initial stimulatory effect of TNF- $\alpha$ on the adhesion of monocytic THP-1 cells to EA.hy926 cultures was significantly increased by the simultaneous presence of Epo (Figure 2A,B).

The previous result led us to investigate if adhesion molecules could be involved in this effect and therefore be upregulated. As expected, mRNA levels of both VCAM-1 and ICAM-1 increased in the presence of TNF- $\alpha$. However, this effect was even higher in cells coincubated with TNF- $\alpha$ and Epo. This demonstrated that when cells were exposed to both cytokines, expression of adhesion molecules was enhanced in parallel with monocyte attachment to activated endothelial cells (Figure 2C,D). It is worth 
A

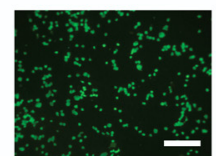

Control

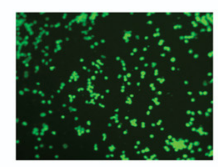

cEpo

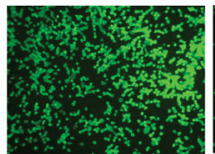

TNF- $\alpha$

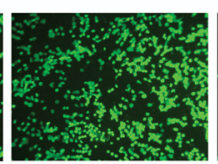

TNF- $\alpha+$ cEpo

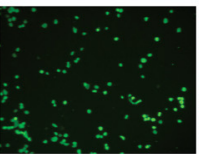

Epo

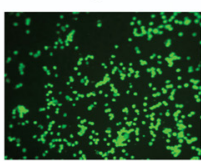

HTLEpo

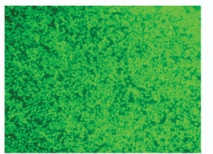

TNF- $\alpha+E$ po

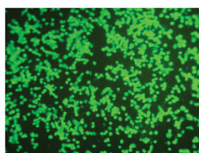

TNF- $\alpha+$ HTLEpo

\section{B}

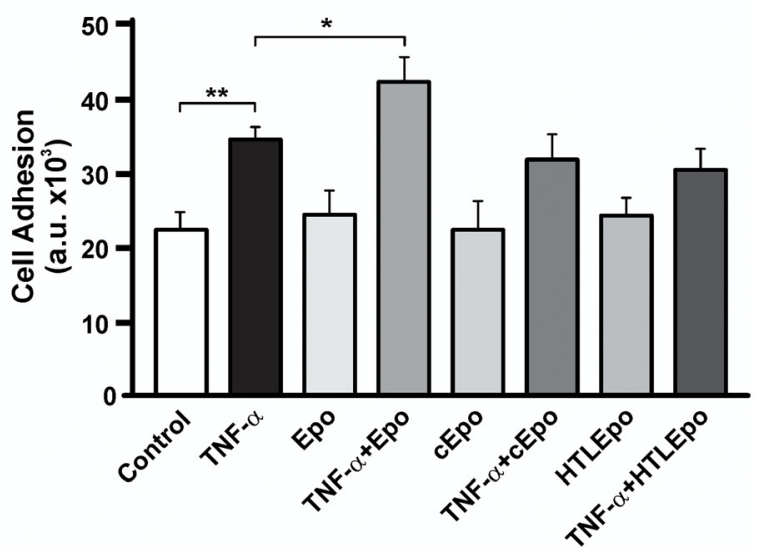

C
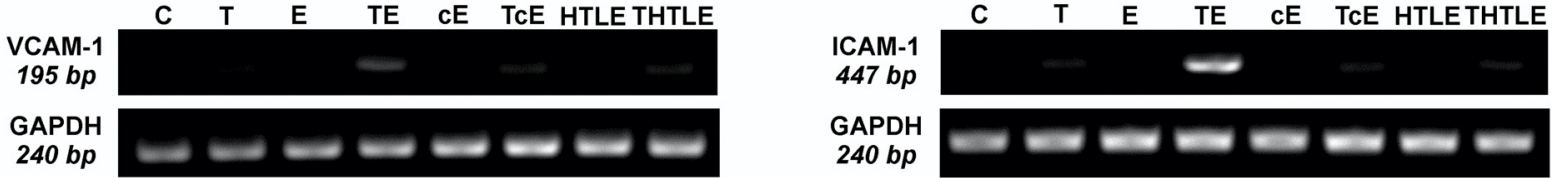

D
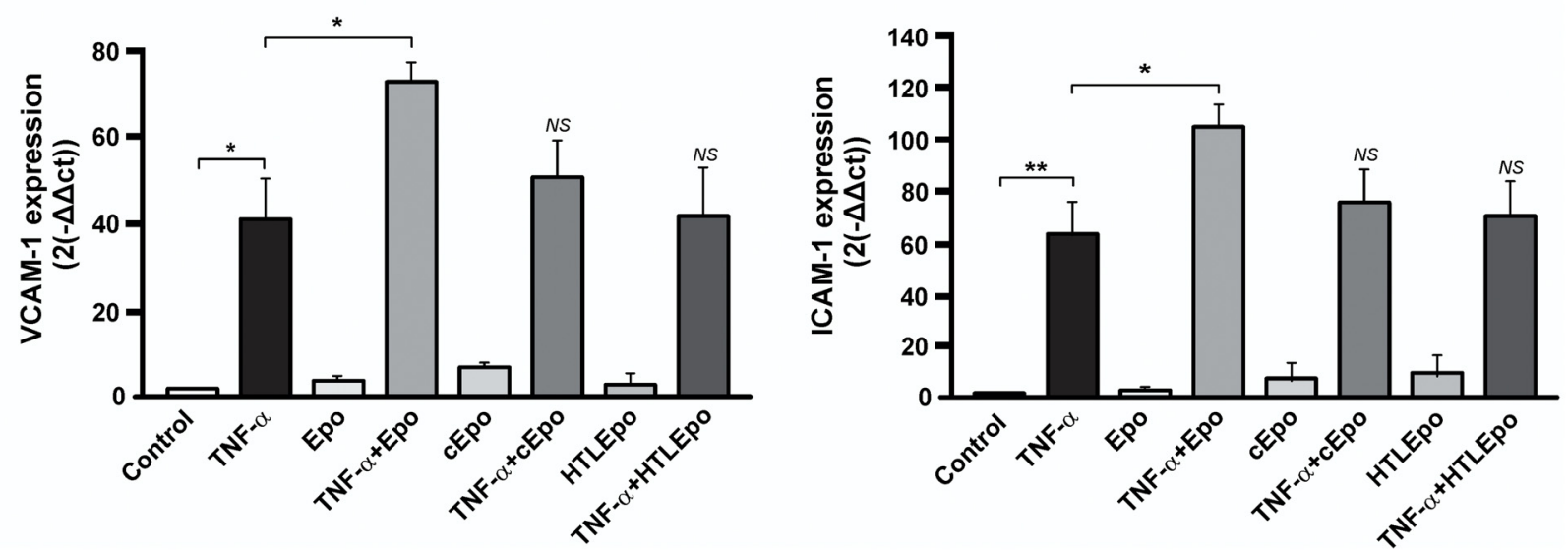

Figure 2: Coincubation with TNF- $\alpha$ and Epo stimulates monocyte adhesion to endothelial cells. EA.hy926 cells were incubated (18 h) with Epo ( 80 or $200 \mathrm{ng} / \mathrm{ml})$, cEpo $(200 \mathrm{ng} / \mathrm{ml})$ or HTLEpo $(200 \mathrm{ng} / \mathrm{ml})$ in the presence or absence of TNF- $\alpha(30 \mathrm{ng} / \mathrm{ml})$, followed by incubation (1 h) with monocytic THP-1 cells for adhesion analysis. (A) Photographs obtained by fluorescence microscopy show adhesion of CFSE-labelled THP-1 cells to TNF- $\alpha$ - and Epo + TNF- $\alpha$-activated endothelial EA.hy926 cells (Bar: $500 \mu \mathrm{m}$ ). (B) Fluorometric quantitation. Bars represent Mean \pm SEM of fluorescence intensity indicated in arbitrary units. Significant differences: ${ }^{*} P<0.05 ;{ }^{* *} P<0.01, n=7$. No significant differences were found between $c$ Epo + TNF- $\alpha$ or HTLEpo + TNF- $\alpha$ versus TNF- $\alpha$. (C, D) Detection of VCAM-1 and ICAM-1 mRNA levels by reverse transcription-PCR followed by agarose gel electrophoresis and real-time PCR. Bars represent Mean \pm SEM of VCAM-1 or ICAM-1 expression at mRNA levels relative to the control gene GAPDH $\left(2^{-\Delta \Delta c}\right)$. Significant differences: ${ }^{*} P<0.05 ;{ }^{* *} P<0.01 ; n=3$, (NS) indicates no significant differences with respect to TNF- $\alpha$.

mentioning that Epo was used at a concentration which was insufficient to stimulate cell migration and which was also unable to induce VCAM-1 and ICAM-1 expression and monocyte adhesion (Figure 2).

Regarding the modified erythropoietins, neither cEpo nor HTLEpo had an effect on cell adhesion or on the expression of the adhesion molecules. The fact that the modified erythropoietins did not exhibit the promigratory effect of the native protein (Figure 1B) or its ability to produce a synergistic effect with TNF- $\alpha$ on the endothelial cell adhesion process (Figure 2) strongly suggests that these alterations in the functionality of Epo can be ascribed to changes in protein structure that lead to the inhibition of the activation of its receptor. 


\section{Study of the erythropoietin receptor}

To investigate the contribution of Epo to the enhanced migratory ability of endothelial cells when simultaneously exposed to Epo and TNF- $\alpha$, we studied the possible activation of the Epo receptor.

Silencing of EpoR in EA.hy926 cells with a specific siRNA caused inhibition of the promigratory effect induced by TNF- $\alpha+$ Epo $(80 \mathrm{ng} / \mathrm{ml})$ in wound healing assays. Similar results were obtained by blocking the receptor with an anti-EpoR antibody (Figure 3), indicating that the presence of the inflammatory cytokine sensitized endothelial cells to a promigratory effect of Epo through the activation of its specific receptor EpoR.

\section{Generation of an oxidative environment}

Among the possible mechanisms underlying cell motility, the rapid generation of small concentrations of ROS has been associated with the migratory response of cells stimulated with cytokines such as the vascular endothelial growth factor (VEGF) (Wang et al. 2011). Therefore, we investigated the involvement of oxidative species in the

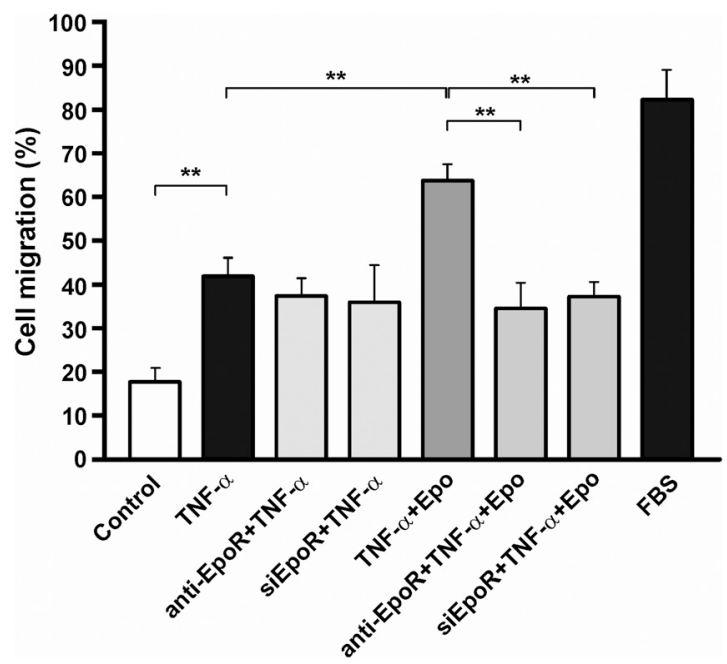

Figure 3: Involvement of Epo receptor in the synergistic effect of both cytokines. EA.hy926 cell migration was evaluated by wound healing assays in the presence of TNF- $\alpha$ with or without Epo. When indicated, cultures were pre-incubated during $1 \mathrm{~h}$ with an anti-EpoR blocking antibody $(400 \mathrm{ng} / \mathrm{ml})$ or transfected with a specific siRNA against EpoR (siEpoR, $100 \mathrm{nM}$ ) $30 \mathrm{~h}$ before the experiment. The conditions used for the inhibition of EpoR, either by siRNA or by a blocking antibody, effectively impaired the promigratory action of Epo $200 \mathrm{ng} / \mathrm{ml}$ (data not shown). Cell cultures without FBS or with $10 \%$ FBS were included as controls. Significant differences: ${ }^{* *} P<0.01, n=5$. promigratory effect of TNF- $\alpha+E p o$. The fact that the antioxidant $N$-acetylcysteine (NAC) prevented EA.hy926 cell migration in wound healing assays stimulated by TNF- $\alpha$ or TNF- $\alpha+$ Epo provides evidence of the participation of ROS in this process (Figure 4A). Moreover, quantification of ROS levels demonstrated that these species were induced by the presence of TNF- $\alpha$, and that they were also significantly increased in cultures stimulated with TNF- $\alpha+$ Epo, an effect which was prevented by preincubation with the antioxidants NAC or ascorbic acid (Figure 4B).

Given thatEpoalonefailed to produce ROS, weinvestigated a possible modulation of TNF- $\alpha$ receptors in order to find an explanation for the increase in oxidant species observed in the presence of TNF- $\alpha+$ Epo compared to TNF- $\alpha$ alone (Figure 4B).

We found that tumor necrosis factor receptor 1 (TNFR1) and tumor necrosis factor receptor 2 (TNFR2) were induced by simultaneous administration of TNF- $\alpha$ and Epo, even though TNFR2 expression was induced in the presence of either TNF- $\alpha$ or Epo alone (Figure 4C). The positive modulation of TNF- $\alpha$ receptors in cells exposed to TNF- $\alpha+$ Epo may explain the increased levels of ROS detected after such treatment (Figure 4B), and suggests a bidirectional modulation between both cytokines.

\section{Expression and activity of the protein PTP1B}

The increased activity of Epo observed in the presence of TNF- $\alpha$ led us to consider a possible signaling deregulation affecting the activation status of its receptor. Protein phosphorylation and dephosphorylation regulate many aspects of the transduction pathways triggered by Epo upon binding to EpoR. Taking into account that protein phosphatases are sensitive to inhibition after generation of ROS, we were interested in investigating whether the production of TNF- $\alpha$-induced ROS could be responsible for PTP1B inactivation, thus making the activity of Epo on endothelial cells more sustained over time.

Experiments on EA.hy926 cell cultures showed that the combination of TNF- $\alpha$ and Epo decreased phosphatase activity and expression of PTP1B when compared with the effect of Epo alone. The induction of PTP1B by Epo was abrogated when TNF- $\alpha$ was simultaneously added to the culture medium (Figure 5A). In assays performed in the presence of both cytokines, a strong inhibition of phosphatase activity was detected in PTP1B immunoprecipitates by colorimetric measurement (Figure 5B).

It can be proposed that generation of ROS by the proinflammatory cytokine facilitates tyrosine-phosphorylationdependent cellular responses by transiently inactivating PTP1B. When the establishment of an oxidative environment 
A

B
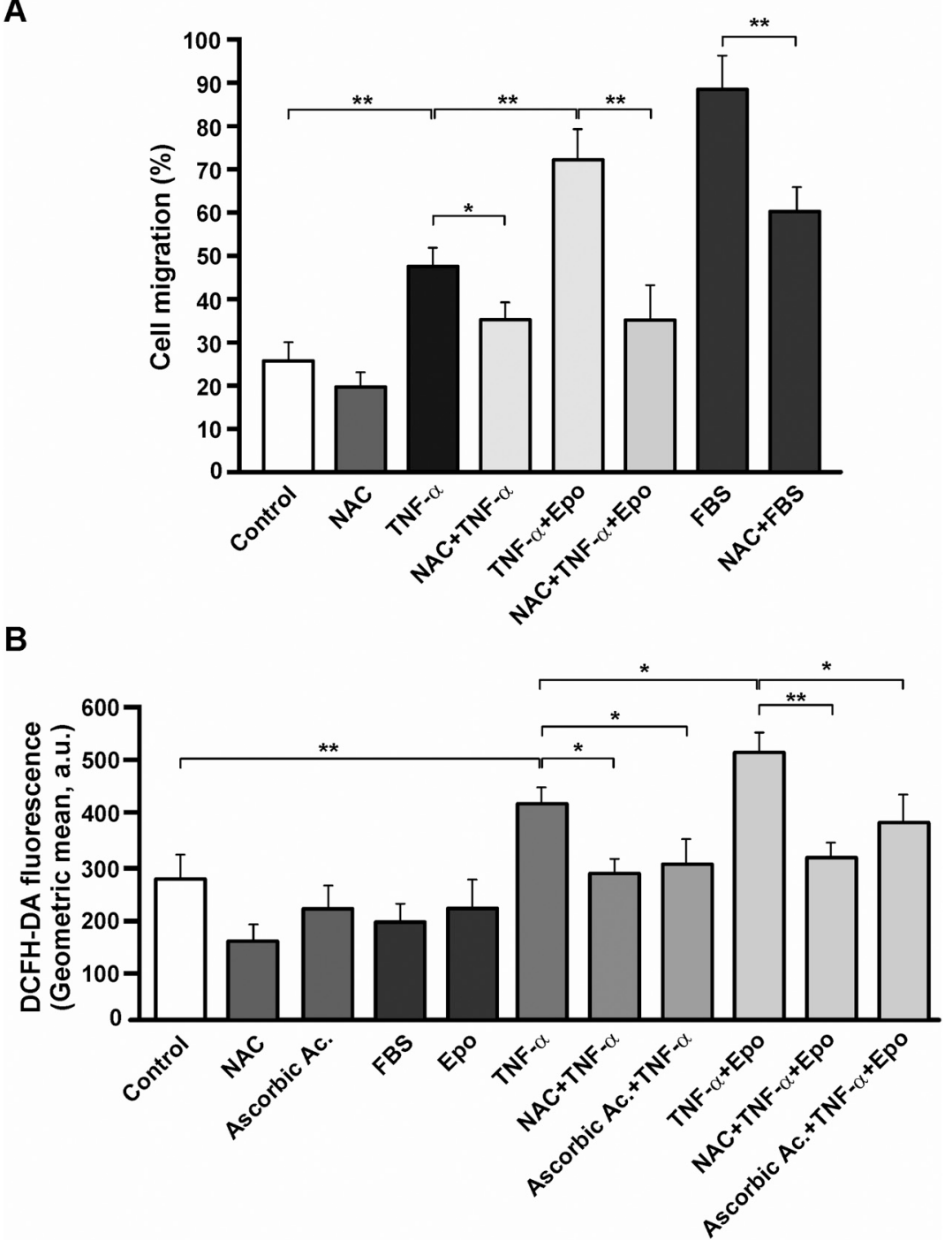

C
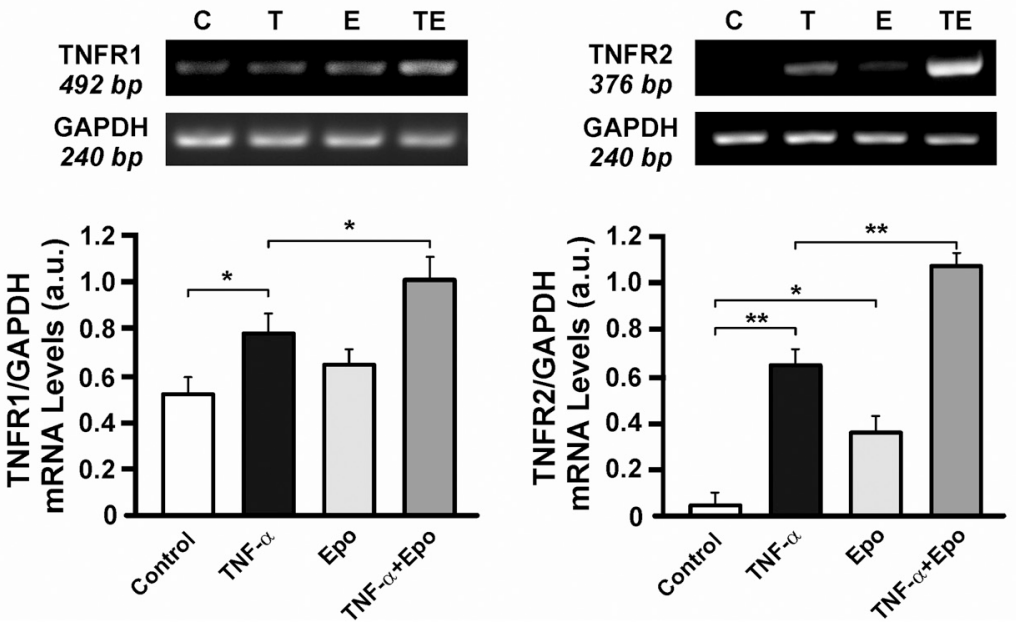

Figure 4: Cell migration is mediated by ROS induced by TNF- $\alpha$. (A) Wound healing assay with or without NAC $(10 \mathrm{mM})$ in cells treated with either TNF- $\alpha$ or Epo + TNF- $\alpha$ ( 80 and $30 \mathrm{ng} /$ $\mathrm{ml}$, respectively). Significant differences: ${ }^{*} P<0.05 ;{ }^{* *} P<0.01, n=5$. (B) ROS content was determined in cells exposed to TNF- $\alpha$ or Epo + TNF- $\alpha$ by flow cytometry with DCFH-DA. Cells were pretreated $(15 \mathrm{~min})$ with the antioxidants NAC (10 $\mathrm{mM})$ or ascorbic acid $(5 \mu \mathrm{M})$. Each bar represents Geometric Mean \pm SEM of fluorescence. Significant differences: ${ }^{*} P<0.05$; ${ }^{* *} P<0.01, n=8$. Controls: cultures without FBS (Control) and with $10 \%$ FBS. (C) TNFR1 and TNFR2 mRNA levels in EA.hy926 cells were determined by reverse transcription-PCR after $18 \mathrm{~h}$ exposure to Epo $(80 \mathrm{ng} / \mathrm{ml}), \mathrm{TNF}-\alpha(30 \mathrm{ng} / \mathrm{ml})$ or both in cell cultures without FBS. PCR products were resolved through agarose gel electrophoresis with ethidium bromide staining. Bars represent Mean \pm SEM of band density. Significant differences: ${ }^{*} P<0.05 ;{ }^{* *} P<0.01$, $n=5$. was not permitted due to preincubation of cell cultures with antioxidants, such as NAC or ascorbic acid, phosphatase activity was recovered (Figure 5B). PTP1B inactivation mediated by TNF- $\alpha$-induced ROS may increase the period of cell activation by Epo, thus contributing to explain why Epo at a low, non-promigratory concentration becomes capable of 
promoting migration when endothelial cells are simultaneously exposed to TNF- $\alpha$.

\section{Signaling pathways involved in the simultaneous induction of cell migration by TNF- $\alpha$ and erythropoietin}

In order to gain a better understanding of the increased sensitivity of endothelial cells to the promigratory activity of Epo in the presence of TNF- $\alpha$, we went on to investigate the underlying mechanisms.

A

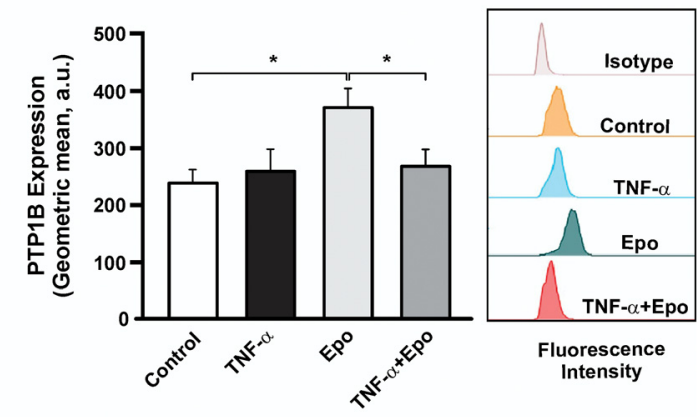

B

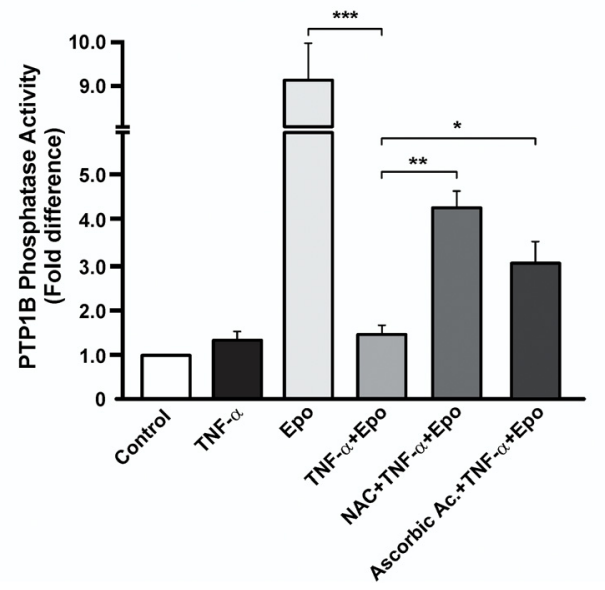

Figure 5: PTP1B inactivation by ROS. (A) Endothelial EA.hy926 cells treated with Epo, TNF- $\alpha$ or both were sequentially exposed to an antiPTP1B primary antibody and to a secondary antibody bound to Alexa Fluor 488, to analyze PTP1B expression by flow cytometry. Each bar represents Geometric Mean \pm SEM of fluorescence. Significant differences: ${ }^{*} P<0.05, n=5$. (B) PTP1B phosphatase activity: EA.hy926 cells were incubated with TNF- $\alpha$, Epo or Epo + TNF- $\alpha$ for $18 \mathrm{~h}$. When pretreated with NAC (10 mM) or ascorbic acid $(5 \mu \mathrm{M})$, antioxidants were added $15 \mathrm{~min}$ before the rest of the treatments. Cell lysates were immunoprecipitated with anti-PTP1B antibody and phosphatase activity was determined in the pellets by measuring absorbance at $520 \mathrm{~nm}$ after reaction with 4-aminoantipyrine and potassium ferrocyanide. The activity was expressed as fold increase with respect to control. Significant differences: ${ }^{*} P<0.05$; ${ }^{* *} P<0.01$, ${ }^{* * *} P<0.001, n=5$.
The use of specific inhibitors of signaling factors such as Ly294002 in the wound healing assay showed that the effect of TNF- $\alpha$ on cell migration is mediated by the activation of the PI3K pathway. However, in the presence of both TNF- $\alpha$ and Epo, the use of AG490 and Ly294002 demonstrates the participation of Jak2 and PI3K, factors involved in the Epo signaling (Figure 6A). In line with previous results by our group (Maltaneri et al. 2017) this implies that the promigratory effect of Epo, enhanced by the presence of TNF- $\alpha$, is mediated by the classical signaling pathway triggered after its binding to the homodimeric receptor (EpoR) $)_{2}$ (Figure 3), consequently eliciting Jak2 and PI3K activation (Figure 6A).

Chronic inflammation, a condition in which the proinflammatory cytokine TNF- $\alpha$ induces expression of endothelial adhesion molecules and recruitment of monocytes to cytokine-activated endothelium, is associated with the activation of NF- $\mathrm{kB}$. The expression of adhesion molecules would be related to the activation of NF- $\kappa B$ dependent on ROS in endothelial cells (Kim et al. 2008). Taking into account that ROS activate NF- $\mathrm{kB}$, we investigated if this pathway is also involved in the synergistic promigratory effect of Epo with the proinflammatory cytokine. Figure 6B shows that the presence of salicylic acid, an inhibitor of the NF-kB pathway, prevented EA.hy926 cell migration induced by either TNF- $\alpha$ or TNF$\alpha+$ Epo.

A positive feedback loop was suggested between the mammalian target of rapamycin (mTOR) and NF-kB during inflammation (Okamoto et al. 2016). In this context, specific inhibition of mTOR by rapamycin confirmed the involvement of this pathway in the increased sensitivity of endothelial cells to a promigratory action of Epo in an inflammatory environment generated by TNF- $\alpha$ (Figure 6B). However, direct activation of NF- $\kappa$ B by TNF- $\alpha$ without involving the mTOR signaling pathway cannot be ruled out.

\section{Discussion}

In the present work, we contributed to identify the mechanisms through which endothelial cells are sensitized to Epo in the presence of TNF- $\alpha$. Epo, a growth factor that promotes survival, proliferation and differentiation of erythroid progenitor cells, has long had therapeutical applications. Despite the benefits of Epo treatment to overcome the anemia associated to different pathologies, a significant number of patients, particularly those with cardiovascular or chronic renal diseases, fail to respond. This effect may be explained by the presence of inflammation, a common feature among the multiple 
A

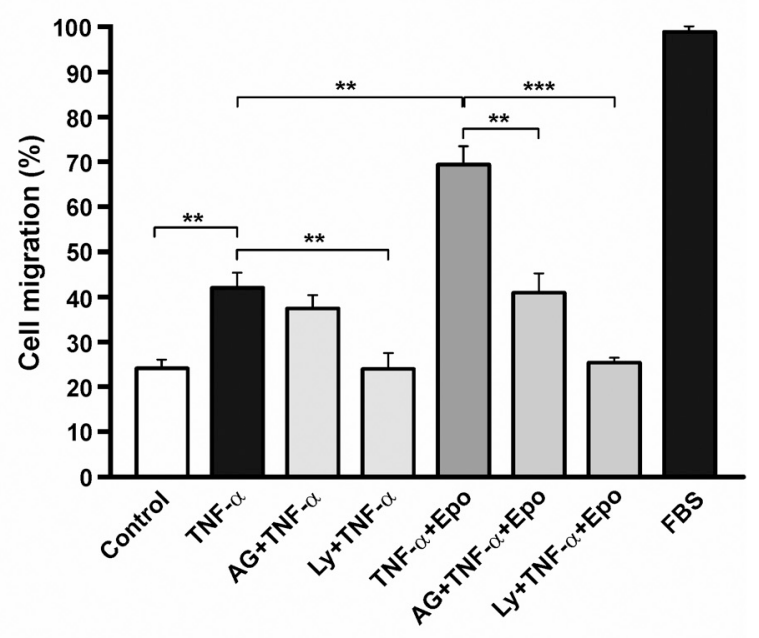

B

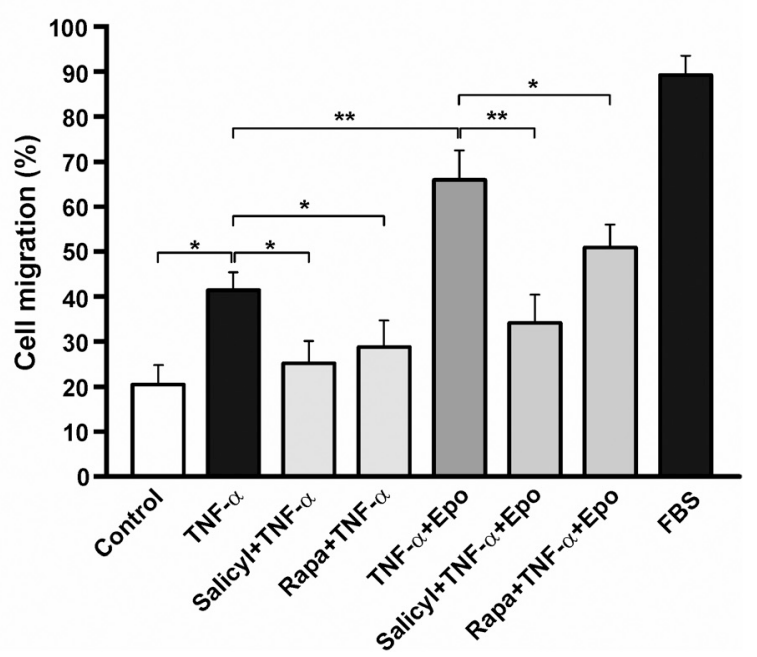

Figure 6: Epo and TNF- $\alpha$ share the same intracellular signaling pathways. The signaling pathways involved in the synergistic effect of Epo + TNF- $\alpha$ were evaluated by cell migration in the presence or absence of inhibitors. (A) Jak2 inhibitor (AG490, $25 \mu \mathrm{M}$ ); PI3K inhibitor (Ly294002, $25 \mu \mathrm{M})$. Significant differences: ${ }^{* *} P<0.01$, ${ }^{* * *} P<0.001, n=5$. (B) IkB phosphorylation inhibitor (salicylic acid, $10 \mu \mathrm{M}$ ); mTOR inhibitor (rapamycin, $100 \mathrm{nM}$ ). Bars represent Mean \pm SEM. Significant differences: ${ }^{*} P<0.05$; $^{* *} P<0.01, n=4$.

mechanisms associated with chronic anemia. It is known that proinflammatory cytokines contribute to the shortening of red blood cell life span, as well as to the inhibition of Epo activity on erythroid cells (Weiss et al. 2019). In other cell types, some stimuli may exert different effects when an inflammatory environment is established. As it has previously been reported, TNF- $\alpha$ is able to induce endothelial cell migration and angiogenesis (Sainson et al. 2008; Shu et al. 2012). Previous research has shown that TNF- $\alpha$ also induces the expression of adhesion molecules, such as VCAM-1 and ICAM-1 (Kim et al. 2008; Lin et al. 2015; Shirai et al. 2018), and stimulates adhesion of the promonocytic U-937 cell line to an endothelial monolayer (Stangl et al. 2001; Yamagata et al. 2015).

When stimulated, endothelial cells exhibit a shift from a quiescent to a proangiogenic phenotype. Given that the processes of cell proliferation and migration respond to inflammation, it can be suggested that proinflammatory cytokines may enhance the effects of promigratory factors. In this context, our present findings demonstrate that Epo, at a concentration which does not normally promote cell migration, acquires the ability to induce the motility of endothelial cells in the presence of TNF- $\alpha$ (Figure 1). This synergistic effect between TNF- $\alpha$ and Epo on EA.hy926 cells was also observed in the upregulation of VCAM-1 and ICAM-1, which subsequently leads to the adhesion of THP-1 monocytes to endothelial cells (Figure 2), a mechanism that in vivo facilitates migration of immune cells to the subendothelial space. Previous studies have shown that Epo enhances endothelial cell migration (Anagnostou et al. 1990; Du et al. 2013; Maltaneri et al. 2017). Taking into account that in our work Epo was used at a concentration which was insufficient to stimulate cell migration (Figure 1), monocyte adhesion or VCAM-1 and ICAM-1 expression (Figure 2), we hypothesized that EA.hy926 endothelial cells are sensitized to a promigratory effect of Epo in the inflammatory environment generated by TNF- $\alpha$.

To explain the synergistic effect of TNF- $\alpha$ and Epo, we first investigated the expression of cellular receptors that mediate the effect of these cytokines on endothelial cells. EpoR activation upon Epo binding was demonstrated by the decrease in cell migration in cultures stimulated with TNF- $\alpha+$ Epo when EpoR was blocked by an anti-EpoR antibody or its expression was knocked down by a siRNA against EpoR (Figure 3). With respect to TNF- $\alpha$ receptors, we observed that both TNFR1 and TNFR2 mRNA levels significantly increased with Epo + TNF- $\alpha$ (Figure 4C), whereas TNFR2 was also augmented in the presence of each of the cytokines separately. Recent evidence suggests that a TNF- $\alpha$-mediated signaling pathway via TNFR1 leads to a proinflammatory state, while TNF- $\alpha$ binding to TNFR2 mainly triggers immune modulation and tissue regeneration (Yang et al. 2018). However, other authors reported that TNF- $\alpha$ promoted cell proliferation and survival in a mouse prostate cancer model through its receptor TNFR1, which induced the activation of the AKT/mTOR and NF- $\mathrm{kB}$ pathways (Galheigo et al. 2016). In line with our results, Taoufik et al. (2008) reported that induction of EpoR expression in primary cortical neurons after glucose deprivation largely depended on TNFR1 and was upregulated by TNF- $\alpha$. In this case, the cell sensitizing effect of TNF- $\alpha$ enhanced the neuroprotective ability of Epo. 
More information related to the signaling pathway involved in the cooperative action of Epo and TNF- $\alpha$ on endothelial cell arose through results of wound healing assays in the presence of inhibitors (Figure 6). Upon binding of their respective ligands, EpoR and TNFR2 may activate the same signaling pathway involving PI3K, and leading to cell proliferation among other effects, as previously reported (Pegoretti et al. 2018; Zhao et al. 2017). This can explain, at least in part, the enhanced migration observed in endothelial cells coincubated with TNF- $\alpha+$ Epo.

The fact that the antioxidants NAC and ascorbic acid prevented cell migration stimulated by either TNF- $\alpha$ or TNF$\alpha+$ Epo in wound healing assays confirmed the involvement of ROS in this process (Figure 4A). These findings were consistent with the levels of intracellular ROS measured by flow cytometry with the DCFH-DA probe, which increased due to treatment with either TNF- $\alpha$ or TNF- $\alpha+$ Epo and were counteracted in the presence of the antioxidants NAC and ascorbic acid (Figure 4B). In this context, it is important to consider that stimulation of vascular endothelial cells by inflammatory cytokines causes the activation of NADPH oxidase, which plays a key role in the generation of ROS (Frey et al. 2009) that activate a variety of redox signaling pathways linked to angiogenesis (Ushio-Fukai 2006).

The finding of ROS involvement in the observed synergistic effect of Epo and TNF- $\alpha$ (Figure 4) on endothelial EA.hy926 cells may be ascribed to the modulation of kinases that converge to the activation of the NF- $\kappa B$ signaling pathway. NF- $\mathrm{kB}$, which is among the most important transcription factors that are activated by oxidative stress (Haddad and Abdel-Karim 2011), is also a downstream element of the PI3K/AKT/mTOR pathway (Lee et al. 2012). The regulatory protein $\mathrm{mTOR}$, involved in the promotion of cell growth, response to nutrients and cell death suppression, is induced in inflammatory conditions, as suggested by experiments in animal models of atherosclerosis (Liu et al. 2011) and skin disease (Buerger et al. 2017). In the present work, Epo and TNF- $\alpha$ were unable to induce cell migration in the presence of inhibitors of the mTOR/NF- $\mathrm{kB}$ pathway, such as rapamycin and salicylate, respectively (Figure 6). Taken together, the results hint at a common activation pathway for both cytokines, thus supporting the synergistic effect between them.

In order to explain the promigratory effect of Epo observed in an inflammatory environment, the finding of ROS generation and overexpression of adhesion molecules as markers of an inflammatory process prompted us to investigate whether oxidative species may affect signaling pathways involved in cell activation via EpoR. Upon activation, negative EpoR regulators downmodulate the cellular response to Epo. Internalization of the receptor, ubiquitination and subsequent degradation by the proteasome is one of the mechanisms involved (Walrafen et al. 2005). Since the phosphorylation of protein tyrosyl residues by protein tyrosine kinases is a critical event in many signaling pathways related to proliferation, differentiation and other biological activities of Epo, PTP become important factors in the downregulation of such activities. Oxidative stress is closely related to PTP regulation, as demonstrated by findings of phosphatase activation or inactivation through ROS. Among these enzymes, PTP1B has been characterized as a negative regulator of cell activation by Epo/EpoR signaling (Callero et al. 2007, 2011; Cohen et al. 2004). PTP1B oxidation mediated by ROS was demonstrated in in vitro and in vivo assays (Bogeski et al. 2006; Lee et al. 1998; Mahadev et al. 2001; Meng et al. 2002; van Montfort et al. 2003) and it has been reported that oxidation of the catalytic Cys residue causes structural modification and inactivation of PTP1B (van Montfort et al., 2003). Based on the hypothesis that signaling downmodulation is involved in the increased promigratory effect of Epo in the presence of TNF- $\alpha$, we investigated if PTP1B expression and/or activity could be modified in an inflammatory environment. As expected, in flow cytometry assays we found induction of PTP1B expression by Epo (Figure 5A), as well as an increase in the PTP1B activity measured in cell immunoprecipitates using anti-PTP1B antibody (Figure 5B). However, these effects were fully abrogated by the simultaneous treatment with Epo and TNF- $\alpha$. The increased enzymatic activity measured in EA.hy926 cell cultures preincubated with the antioxidants NAC or ascorbic acid and then exposed to TNF$\alpha+$ Epo confirms the hypothesis that ROS decreases PTP1B activation (Figure 5B). These results are in accordance with data reported by Mußbach et al. (2015), showing that inhibition of ROS by NAC prevented the abrogation of PTP1B induced by PAR1-AP and the PAR4-AP in Hep3B cells. This way, the reversible oxidation of the enzyme in an inflammatory context may explain PTP1B inactivity.

In previous works of our group, we demonstrated that structural alterations in the Epo molecule, either by carbamylation (cEpo) or by $N$-homocysteinylation (HTLEpo), did not allow the modified proteins to behave in the same way as the native one. While cEpo maintains the antiapoptotic ability of Epo in neuronal cell cultures, it fails to act as an erythropoietic growth factor or as a stimulus for endothelial cell migration (Chamorro et al. 2013, 2015; Maltaneri et al. 2017). On the other hand, the reaction of lysine residues in the Epo molecule with homocysteine thiolactone induces protein aggregation that prevents an adequate Epo/EpoR interaction (Schiappacasse et al. 2018). In the present work, the modified erythropoietins did not exhibit promigratory action even 
at high concentration $(200 \mathrm{ng} / \mathrm{ml})$, and failed to produce a synergistic effect with TNF- $\alpha$ (Figure 1). The inability of cEpo and HTLEpo to exert the same biological effects of the native Epo was also reflected in assays where such derivatives failed to induce the expression of adhesion molecules in EA.hy926 cells as well as the adhesion of THP-1 cells to the endothelial monolayers (Figure 2). Therefore, these results should be taken into consideration in the treatment of renal and cardiovascular patients undergoing Epo therapy who may concurrently show hyperhomocysteinemia or high levels of urea.

\section{Conclusions}

The increased sensitivity of endothelial cells to a promigratory effect of Epo in an inflammatory environment generated by TNF- $\alpha$ may be ascribed to a cascade of events. The simultaneous treatment of TNF- $\alpha$ with a low, nonpromigratory concentration of Epo not only stimulated cell migration, but also the expression of adhesion molecules, thus increasing monocyte adhesion. The results demonstrate the involvement of the classical signaling of cell activation by Epo and the participation of the NF- $\mathrm{kB}$ and mTOR pathways in the effect of Epo and TNF- $\alpha$ on the endothelial EA.hy926 cell line (Figure 7). Moreover, not only EpoR but also TNFR1 and TNFR2 are involved in the increased cell migration induced in the presence of TNF- $\alpha$ + Epo. The finding of signaling pathways shared by Epo and TNF- $\alpha$, as well as the generation of reactive oxygen species by TNF- $\alpha$ provides an explanation for the synergistic action of both cytokines. As ROS inhibit PTP1B, lower levels of PTP1B activity allow Epo/ EpoR signaling to last longer and therefore the cell remains activated by Epo for an extended period, thus causing the activation of common signals. These results demonstrate that the proangiogenic ability of Epo may be enhanced in a proinflammatory environment where TNF- $\alpha$ is released. This may favor the action of Epo as a vascular protectant in ischemia and as a mediator of leukocyte migration dependent on adhesion molecules. However, such effects may be carefully considered in some pathophysiological entities in which tumor angiogenesis or excessive leukocyte adhesion becomes a risk factor.

\section{Materials and methods}

\section{Materials and reagents}

All the chemicals used were of analytical grade. Iscove's modified Dulbecco's medium (IMDM), RPMI-1640 medium, penicillin- streptomycin and TrypLE were obtained from Gibco-Thermo Fisher Scientific (Waltham, MA, USA). Fetal bovine serum (FBS) was from Natocor (Córdoba, Argentina). TNF- $\alpha$, Cytofix/Cytoperm and Perm Wash buffer were from BD Biosciences (San José, CA, USA). NAC, rapamycin, HTL and DCFH-DA were obtained from Sigma-Aldrich (St. Louis, MO, USA). Ascorbic acid was from Carlo ERBA (Sabadell, Spain). The antibodies against EpoR (M-20, sc-697) and PTP1B (H-135, sc-14021), as well as the siRNA targeting EpoR (sc-37092) and the siRNA against green fluorescent protein (GFP) (sc-45924) were from Santa Cruz Biotechnology (CA, USA). The inhibitors Ly294002 and AG490 were obtained from Calbiochem/Millipore (County Cork, Ireland). The reverse transcription kit containing Moloney Murine Leukemia Virus (M-MLV) reverse transcriptase, Ribonuclease inhibitor and oligodTs was from Promega (Madison, WI, USA). Specific primers for ICAM-1, VCAM-1, TNFR1, TNFR2 and glyceraldehyde-3phosphate dehydrogenase (GAPDH), the TRIzol reagent, the fluorescent probe carboxyfluorescein succinimidyl ester (CFSE), the transfection reagent Lipofectamine 3000, the transfection culture medium OptiMEM and the secondary antibody conjugated with Alexa Fluor 488 were from Invitrogen Life Technologies (Waltham, MA, USA). Phosphatase activity was measured with an alkaline phosphatase kit from Wiener lab (Warsaw, Poland). Recombinant human erythropoietin was kindly supplied by Zelltek (specific activity: $125 \mathrm{IU} / \mu \mathrm{g}$; $\mathrm{Mr}=30,243$ as determined by MALDITOF MS) (Santa Fe, Argentina).

\section{Carbamylation and $\mathbf{N}$-homocysteinylation of erythropoietin}

The structural transformation of Epo by carbamylation with potassium cyanate was performed as described by Leist et al. (2004) with modifications made in our laboratory (Chamorro et al. 2013). For $N$-homocysteinylation, Epo was incubated in the presence of HTL at an Epo: HTL molar ratio of 1:500 in phosphate buffered saline (PBS) for $24 \mathrm{~h}$ at $37^{\circ} \mathrm{C}$. Purification was performed as described before (Schiappacasse et al. 2018).

Analysis by capillary zone electrophoresis (Beckman Coulter, Carlsbad, CA, USA) revealed structural changes in comparison to the native protein. Since carbamylation and $N$-homocysteinylation -due to reaction with potassium cyanate or HTL, respectively - caused the

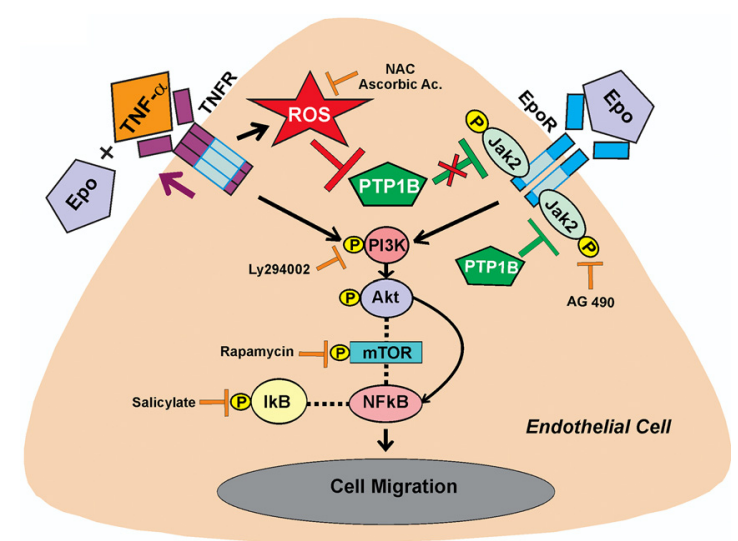

Figure 7: Schematic illustration of the proposed mechanisms involved in the simultaneous induction of cell migration by TNF- $\alpha$ and Epo. 
transformation of the lysine residues of Epo, cEpo and HTLEpo displayed an increased electrophoretic mobility compared to Epo, which is explained by the expected loss of positive net charge of the molecule (data not shown).

\section{Cell cultures}

The endothelial cell line EA.hy926, derived from the fusion of human umbilical vein endothelial cells (HUVEC) and the adenocarcinoma cell line A549 (Edgell et al. 1983), was kindly supplied by Dr. Fernanda Parborell (IBYME-CONICET, Buenos Aires, Argentina) with permission from Dr. Gareth Owen (Pontificia Universidad Católica, Chile). Cultures were maintained on IMDM supplemented with $10 \%$ heat-inactivated FBS (v/v), $100 \mathrm{U} / \mathrm{ml}$ penicillin and $100 \mu \mathrm{g} / \mathrm{ml}$ streptomycin. Cells were subcultured upon reaching $80-90 \%$ confluence and were used up to passage 18 , due to cell senescence. In order to replicate the physiological quiescent state of the endothelium, cells were deprived of FBS before treatment, and experiments were carried out in FBS-free medium.

The human monocitic cell line THP-1 (ATCC TIB-202), derived from an acute monocytic leukemia, was cultured in RPMI 1640 medium supplemented with $10 \%$ heat-inactivated FBS $(\mathrm{v} / \mathrm{v})$, penicillin $100 \mathrm{U} / \mathrm{ml}$, streptomycin $100 \mu \mathrm{g} / \mathrm{ml}, 1 \%$ glutamine, $250 \mathrm{mg} / \mathrm{ml}$ glucose, $11 \mathrm{mg} / \mathrm{l}$ sodium pyruvate and $50 \mu \mathrm{M} \beta$-mercaptoethanol. Cultures were maintained at a density of $1.5 \times 10^{5}$ cells $/ \mathrm{ml}$. When treated with phorbol 12-myristate 13-acetate (PMA), THP-1 cells acquire the morphological and functional features of macrophages, such as adherence to crystal surfaces.

All cell cultures were maintained at $37{ }^{\circ} \mathrm{C}$ and $5 \% \mathrm{CO}_{2}$, with replacement of culture media every three days.

\section{Cell migration (wound healing) assay}

Cells were seeded on 24-well plates (80,000 viable cells/well) and allowed to attach overnight on growth medium. After washing with PBS, cells were FBS-deprived for $18 \mathrm{~h}$ before practicing a scratch with a pipette tip and adding the corresponding treatments. FBS (10\%) was added as a cell migration control. Images were obtained at the beginning $(t=0)$ and at the end of the experiment $(t=18 \mathrm{~h})$ using an inverted microscope Axiovert 135 (Carl Zeiss, Birkerød, Denmark) and a Nikon Coolpix 5000 camera, and digitalized with the Axiovision software (Birkerød, Denmark). For each independent experiment, cell migration was quantified by averaging four different fields per treatment. Inhibitors were added at least $15 \mathrm{~min}$ before the assays.

A $18 \mathrm{~h}$ incubation was chosen so that the contribution of cell proliferation to wound closure would be insignificant, according to our previous studies on EA.hy926 cell growth (Maltaneri et al. 2017).

\section{Cell adhesion}

THP- 1 cultures (approximately $10^{5}$ cells) were labeled with CFSE (0.5 $\mu \mathrm{M}$ in PBS) for $15 \mathrm{~min}$ at $37^{\circ} \mathrm{C}$. Subsequently, cells were washed twice with RPMI medium and resuspended in $100 \mu \mathrm{l}$ of medium before being added to EA.hy926 cultures for $1 \mathrm{~h}$. Then, to remove nonadherent cells, each well was carefully washed by addition of prewarmed RPMI, followed by gentle swirling and inversion of the plate and blotting of excess liquid onto absorbent paper. This was repeated three times, and $100 \mu \mathrm{l}$ of PBS were added to each well. The images were taken with the fluorescent microscope Axiovert 135 (Carl Zeiss) coupled with a Nikon Coolpix 5000 camera. Relative fluorescence was measured using an Optima FluorSTAR fluorometer (BMG Labtech, Offenburg Germany) set at $485 \mathrm{~nm}$ excitation wavelength and $530 \mathrm{~nm}$ emission wavelength.

\section{RNA isolation, reverse transcription and real time-PCR}

RNA extraction was performed using the TRIzol reagent, according to manufacturer's protocol. Nucleic acid quantification was performed using NanoDrop equipment (Thermo Scientific, MA, USA). RNA samples with a 260/280 nm ratio above 1.80 and a 230/260 nm ratio close to 0.5 were considered pure from protein and organic contaminants, respectively. Reverse transcription of $1 \mu \mathrm{g}$ total RNA was M-MLV reverse transcriptase. PCR master mixes were prepared with $1.5 \mathrm{mM} \mathrm{MgCl}_{2}, 0.2 \mathrm{mM}$ dNTPs and the corresponding primers at $0.25 \mathrm{mM}$ (final concentrations). The sequences of the primers used were as follows: VCAM-1, forward: $5^{\prime}$ - TTGGGAACGAACACTCTTACCTG-3', reverse: 5'-AGTCTATCTCCAGCCTGTCAAATG-3' (195 bp); ICAM-1, forward: 5'-CGTGCCGCACTGAACTGGAC-3', reverse: 5'CCTCACACTTCACTGTCACCT-3' (447 bp); TNFR1, forward: $5^{\prime}$-TCGATTTGCTGTACCAAGTG-3', reverse: 5'- GAAAATGACCAGGGGCAACAG-3' (492 bp); TNFR2, forward: 5'-CCAGTGCGTTGGACAGAA-3', reverse: 5'-GGCTTCATCCCAGCATCA-3' (376 bp) and GAPDH, forward: $5^{\prime}$-TGATGACATCAAGAAGGTGGTGAAG-3', reverse: 5'-TCCTTGGAGGCCATGTAGGCCAT-3' (240 bp). Amplification of VCAM-1 consisted of 40 cycles of denaturation at $95^{\circ} \mathrm{C}$ for $10 \mathrm{~s}$, annealing at $56^{\circ} \mathrm{C}$ for $30 \mathrm{~s}$ and extension at $72^{\circ} \mathrm{C}$ for $20 \mathrm{~s}$; ICAM- 1 consisted of 40 cycles of denaturation at $95^{\circ} \mathrm{C}$ for $15 \mathrm{~s}$, annealing at $60^{\circ} \mathrm{C}$ for $15 \mathrm{~s}$ and extension at $72^{\circ} \mathrm{C}$ for $25 \mathrm{~s}$. The program used for TNFR1 consisted of 35 cycles of denaturation at $94^{\circ} \mathrm{C}$ for $1 \mathrm{~min}$, annealing at $53^{\circ} \mathrm{C}$ for $2 \mathrm{~min}$ and extension at $72^{\circ} \mathrm{C}$ for $2 \mathrm{~min}$, and TNFR2 consisted of 35 cycles of denaturation at $94^{\circ} \mathrm{C}$ for $1 \mathrm{~min}$, annealing at $56^{\circ} \mathrm{C}$ for $1 \mathrm{~min}$ and extension at $72{ }^{\circ} \mathrm{C}$ for $1 \mathrm{~min}$. PCR products were resolved on $2 \%$ agarose gels stained with $0.05 \%$ ethidium bromide. Fluorescence of DNA was detected with a G:BOX Chemi system and digitalized using the GeneSys software (Syngene, Cambridge, UK). Relative quantification of mRNA levels was performed through band densitometry with the ImageJ software, using GAPDH as a housekeeping gene.

Real time PCR was carried out in a My IQ2 thermocycler (Bio-Rad, Hercules, CA, USA), and results were analyzed using the CFX software (Bio-Rad). The relative gene expression levels were determined using the threshold cycle (CT) method ( $2^{-\Delta \Delta \mathrm{CT}}$ method) normalized to the endogenous control gene GAPDH.

\section{ROS levels by flow cytometry}

At the end of treatments, EA.hy926 cells were washed with PBS at room temperature and incubated $\left(30 \mathrm{~min}, 37^{\circ} \mathrm{C}\right)$ with DCFH-DA $(20 \mu \mathrm{M}$ in $\mathrm{PBS})$. Cells were then collected with TrypLE, centrifuged and fixed in $0.5 \%$ paraformaldehyde/PBS. Event acquisition was performed in a flow cytometer (FACS Aria II, BD, San José, CA, USA). Data were analyzed using the FlowJo software (FlowJo LLC, Turku, Finland).

\section{PTP1B expression by flow cytometry}

After experimental treatments, EA.hy926 cells were collected by centrifugation and washed with $2 \%$ FBS in PBS. Cells were then 
incubated with Cytofix-Cytoperm for $20 \mathrm{~min}$ and centrifuged (350 g, $10 \mathrm{~min}$ ) before adding an anti-PTP1B antibody $\left(30 \mathrm{~min}, 4^{\circ} \mathrm{C}\right)$. Samples were washed with Perm Wash buffer and then incubated with an Alexa Fluor 488-bound secondary antibody $\left(30 \mathrm{~min}, 4^{\circ} \mathrm{C}\right)$. Events were acquired in a FACS Aria II flow cytometer (BD, San José, CA, USA) and data were analyzed using the FlowJo software (FlowJo LLC).

\section{Phosphatase activity}

Protein immunoprecipitation: Cells were washed with ice-cold PBS and lyzed in a hypotonic buffer ( $50 \mathrm{mM}$ Tris pH 8.0, $150 \mathrm{mM} \mathrm{NaCl}, 1 \%$ Triton $\mathrm{X}-100$ ) containing protease inhibitors (1 mM PMSF, $4 \mu \mathrm{M}$ leupeptin, $2 \mu \mathrm{M}$ pepstatin), in a ratio of $200 \mu \mathrm{l} / 10^{7}$ cells. After $30 \mathrm{~min}$ of incubation on ice, samples were centrifuged $(15,000 \mathrm{~g}, 15 \mathrm{~min})$ to remove insoluble material. Cell lysate aliquots equivalent to $1 \mathrm{mg}$ total protein were immunoprecipitated with anti-PTP1B antibody at $2 \mu \mathrm{g} / \mathrm{ml}$ final concentration ( $4{ }^{\circ} \mathrm{C}$ for $1 \mathrm{~h}$ with gentle agitation). Protein A-agarose was added and, after overnight incubation with rotation at $4^{\circ} \mathrm{C}$, immunocomplexes were collected by centrifugation at $15,000 \mathrm{~g}$ for $15 \mathrm{~min}$.

PTP1B activity: The activity of PTP1B in the immunoprecipitates was determined by incubation at $37^{\circ} \mathrm{C}$ for 10 min using an alkaline phosphatase kit in which the enzyme breaks the sodium phenylphosphate. The freed phenol reacts with 4-aminoantipyrine and potassium ferricyanide yielding a colored product. The color intensity, which is proportional to the enzymatic activity, was measured at $520 \mathrm{~nm}$ in a microplate reader (Bio-Rad, Hercules, CA, USA).

\section{Silencing of EpoR with siRNA}

Pre-manufactured siRNA duplexes targeting EpoR were delivered into EA.hy926 cells with Lipofectamine 3000, according to manufacturer's instructions. Preliminary assays carried out in EA.hy926 cultures allowed us to determine an optimal final concentration of $100 \mathrm{nM}$ for EpoR silencing. We observed a decrease in mRNA levels (RT-PCR) as early as $24 \mathrm{~h}$ post-transfection, although EpoR protein expression was at its lowest after $48 \mathrm{~h}$ (data not shown). Based on these optimization assays, cultures were transfected with the siRNA before the onset of the wound-healing experiments, so that the $18 \mathrm{~h}$ incubation would coincide with the period of EpoR downregulation. The conditions used correspond to $88 \%$ of the EpoR silencing (data not shown). As a transfection and knock-down control, a pre-manufactured siRNA against the green fluorescent protein (GFP) was used at the same final concentration (data not shown).

To deliver the siRNAs into the cells, cultures were incubated in OptiMEM medium $1 \mathrm{~h}$ before the addition of Lipofectamine $3000+$ siRNA complexes for $6 \mathrm{~h}$, at the end of which the medium was replaced with $10 \%$ FBS-supplemented IMDM without antibiotics.

\section{Statistics}

The Graph Pad Prism software (GraphPad Software Inc.) was used for statistical analysis. Results are expressed as mean \pm standard error of the mean (Mean \pm SEM) of three or more independent experimental replicates. Kruskal-Wallis one-way analysis of variance was followed by Dunn's test for comparison among groups. Least significant difference with $P<0.05$ was the criterion for statistical significance.
Acknowledgments: This work was supported by grants from the Universidad de Buenos Aires (UBACYT), the Consejo Nacional de Investigaciones Científicas y Técnicas (CONICET) and the Agencia Nacional de Promoción Científica y Tecnológica (ANPCYT). The authors are grateful to Zelltek S.A. (Argentina) for supplying human recombinant erythropoietin. Dr. Alcira Nesse, Dr. Daniela Vittori and Dr. María Eugenia Chamorro are research scientists at the CONICET, and Dr. Romina Maltaneri and Lic. Agustina Schiappacasse have received fellowships from the CONICET (Argentina).

Author contribution: All the authors have accepted responsibility for the entire content of this submitted manuscript and approved submission.

Research funding: This research was funded by the Universidad de Buenos Aires (UBACYT), the Consejo Nacional de Investigaciones Científicas y Técnicas (CONICET) and the Agencia Nacional de Promoción Científica y Tecnológica (ANPCYT).

Employment or leadership: None declared.

Honorarium: None declared.

Conflict of interest statement: The authors declare that they have no existing conflicts of interest regarding this article.

\section{References}

Anagnostou, A., Lee, E.S., Kessimian, N., Levinson, R., and Steiner, M. (1990). Erythropoietin has a mitogenic and positive chemotactic effect on endothelial cells. Proc. Natl. Acad. Sci. U. S. A. 87: 5978-5982.

Bogeski, I., Bozem, M., Sternfeld, L., Hofer, H.W., and Schulz, I. (2006). Inhibition of protein tyrosine phosphatase $1 B$ by reactive oxygen species leads to maintenance of $\mathrm{Ca}^{2+}$ influx following store depletion in HEK 293 cells. Cell Calcium 40: 1-10.

Buerger, C., Shirsath, N., Lang, V., Berard, A., Diehl, S., Kaufmann, R., Boehncke, W.H., and Wolf, P. (2017). Inflammation dependent mTORC1 signaling interferes with the switch from keratinocyte proliferation to differentiation. PloS One 12: e0180853.

Callero, M., Pérez, G.M., Vittori, D.C., Vota, D.M., Pregi, N., and Nesse, A.B. (2007). Modulation of protein tyrosine phosphatase $1 B$ by erythropoietin in UT-7 cell line. Cell. Physiol. Biochem. 20: 319328.

Callero, M., Vota, D.M., Chamorro, M.E., Wenker, S.D., Vittori, D.C., and Nesse, A.B. (2011). Calcium as a mediator between erythropoietin and protein tyrosine phosphatase 1B. Arch. Biochem. Biophys. 505: 242-249.

Chamorro, M.E., Wenker, S., Vota, D., Vittori, D., and Nesse, A. (2013). Signaling pathways of cell proliferation are involved in the differential effect of erythropoietin and its carbamylated derivative. Biochim. Biophys. Acta Mol. Cell Res. 1833: 19601968.

Chamorro, M.E., Maltaneri, R., Vittori, D., and Nesse, A. (2015). Protein tyrosine phosphatase 1B (PTP1B) is involved in the defective 
erythropoietic function of carbamylated erythropoietin. Inter. J. Biochem. Cell. Biol. 61: 63-71.

Cohen, J., Oren-Young, L., Klingmuller, U., and Neumann, D. (2004). Protein tyrosine phosphatase $1 \mathrm{~B}$ participates in the downregulation of the erythropoietin receptor signaling. Biochem. J. 377: 517-524.

Doleschel, D., Rix, A., Arns, S., Palmowski, K., Gremse, F., Merkle, R., Salopiata, F., Klingmüller, U., Jarsch, M., Kiessling, F., et al. (2015). Erythropoietin improves the accumulation and therapeutic effects of carboplatin by enhancing tumor vascularization and perfusion. Theranostics 5: 905-918.

Du, G., Zhu, H., Yu, P., Wang, H., He, J., Ye, L., Fu, F., Zhang, J., and Tian, J. 2013. SMND-309 promotes angiogenesis in human umbilical vein endothelial cells through activating erythropoietin receptor/ STAT3/VEGF pathways. Eur. J. Pharmacol. 700: 173-180.

Edgell, C.J., Mc Donald, C.C., and Graham, J.B. (1983). Permanent cell line expressing human factor VIII-related antigen established by hybridization. Proc. Natl. Acad. Sci. U. S. A. 80: 3734-3737.

Frey, R.S., Ushio-Fukai, M., and Malik, A.B. 2009. NADPH oxidasedependent signaling in endothelial cells: role in physiology and pathophysiology. Antioxid. Redox Signal. 11: 791-810.

Galheigo, M.R., Cruz, A.R., Cabral, Á.S., Faria, P.R., Cordeiro, R.S., Silva, M.J., Tomiosso, T.C., Gonçalves, B.F., Pinto-Fochi, M.E., Taboga, S.R., et al. (2016). Role of the TNF- $\alpha$ receptor type 1 on prostate carcinogenesis in knockout mice. Prostate 76: 917926.

Haddad, J.J., and Abdel-Karim, N.E. (2011). NF-kB cellular and molecular regulatory mechanisms and pathways: therapeutic pattern or pseudoregulation? Cell Immunol. 271: 5-14.

Kim, H., Hwang, J., Woo, C.H., Kim, E., Kim, T., Cho, K., Kim, J.H., Seo, J.M., and Lee, S.S. (2008). TNF- $\alpha$-induced up-regulation of intercellular adhesion molecule-1 is regulated by a Rac-ROSdependent cascade in human airway epithelial cells. Exper. Mol. Med. 40: 167-175.

Kraus, L.M., Jones, M.R., and Kraus, A.P., Jr. (1998). Essential carbamoyl-amino acids formed in vivo in patients with end-stage renal disease managed by continuous ambulatory peritoneal dialysis: isolation, identification, and quantitation. J. Lab. Clin. Med. 131: 425-431.

Lee, K.B., Byun, H.J., Park, S.H., Park, C.Y., Lee, S.H., and Rho, S.B. (2012). CYR61 controls p53 and NFkB expression through PI3K/ Akt/mTOR pathways in carboplatin induced ovarian cáncer cells. Cancer Lett. 315: 86-95.

Lee, S.R., Kwon, K.S., Kim, S.R., and Rhee, S.G. (1998). Reversible inactivation of protein-tyrosine phosphatase $1 B$ in A431 cells stimulated with epidermal growth factor. J. Biol. Chem. 273: 15366-15372.

Leist, M., Ghezzi, P., Grasso, G., Bianchi, R., Villa, P., Fratelli, M., Savino, C., Bianchi, M., Nielsen, J., Gerwien, J., et al. (2004). Derivatives of erythropoietin that are tissue protective but not erythropoietic. Science 305: 239-242.

Lin, C.C., Pan, C.S., Wang, C.Y., Liu, S.W., Hsiao, L.D., and Yang, C.M. (2015). Tumor necrosis factor-alpha induces VCAM-1 mediated inflammation via c-Src-dependent transactivation of EGF receptors in human cardiac fibroblasts. J. Biomed. Sci. 15: 22-53.

Liu, J., Ma, K., Gao, M., Zhang, X., and Liu, B. (2011). The activation of mTOR pathway induced by inflammation accelerates the progression of atherosclerosis in hemodialysis patients. Int. J. Cardiol. 152: S5-S6.
Mahadev, K., Zilbering, A., Zhu, L., and Goldstein, B.J. (2001). Insulinstimulated hydrogen peroxide reversibly inhibits proteintyrosine phosphatase $1 \mathrm{~b}$ in vivo and enhances the early insulin action cascade. J. Biol. Chem. 276: 21938-21942.

Maltaneri, R., Chamorro, M.E., Schiappacasse, A., Nesse, A., and Vittori, D. (2017). Differential effect of erythropoietin and carbamylated erythropoietin on endothelial cell migration. Int. J. Biochem. Cell Biol. 85: 25-34.

Maltaneri, R., Schiappacasse, A., Chamorro, M.E., Nesse, A., and Vittori, D. (2018). Participation of membrane calcium channels in erythropoietin-induced endothelial cell migration. Eur. J. Cell Biol. 97: 411-421.

Meng, T.C., Fukada, T., and Tonks, N.K. (2002). Reversible oxidation and inactivation of protein tyrosine phosphatases in vivo. Mol. Cell 9: 387-399.

Mußbach, F., Henklein, P., Westermann, M., Settmacher, U., Böhmer, F.D., and Kaufmann, R. (2015). Proteinase-activated receptor 1 and 4 promoted migration of Hep3B hepatocellular carcinoma cells depends on ROS formation and RTK transactivation. J. Cancer Res. Clin. Oncol. 141: 813-825.

Myers, M.P., Andersen, J.N., Cheng, A., Tremblay, M.L., Horvath, C.M., Parisien, J.P., Salmeen, A., Barford, D., and Tonks, N.K. 2001. TYK2 and JAK2 are substrates of protein-tyrosine phosphatase 1B. J. Biol. Chem. 276: 47771-47774.

Okamoto, T., Ozawa, Y., Kamoshita, M., Osada, H., Toda, E., Kurihara, T., Nagai, N., Umezawa, K., and Tsubota, K. (2016). The neuroprotective effect of rapamycin as a modulator of the mTORNF-KB axis during retinal inflammation. PLoS One 11: e0146517.

Pegoretti, V., Baron, W., Laman, J.D., and Eisel, U.L.M. (2018). Selective modulation of TNF-TNFRs signaling: insights for multiple sclerosis treatment. Front. Immunol. 9: 925.

Sainson, R.C., Johnston, D.A., Chu, H.C., Holderfield, M.T., Nakatsu, M.N., Crampton, S.P., Davis, J., Conn, E., and Hughes, C.C. (2008). TNF primes endothelial cells for angiogenic sprouting by inducing a tip cell phenotype. Blood 111: 4997-5007.

Schiappacasse, A., Maltaneri, R., Chamorro, M.E., Nesse, A., Wetzler, D., and Vittori, D. (2018). Modification of erythropoietin structure by $\mathrm{N}$-homocysteinylation affects its antiapoptotic and proliferative functions. FEBS J. 285: 3801-3814.

Shirai, R., Sato, K., Yamashita, T., Yamaguchi, M., Okano, T., Watanabe-Kominato, K., Watanabe, R., Matsuyama, T.A., Ishibashi-Ueda, H., Koba, S., et al. (2018). Neopterin counters vascular inflammation and atherosclerosis. J. Amer. Heart Assoc. 7: e007359.

Shu, Q., Amin, M.A., Ruth, J.H., Campbell, P.L., and Koch, A.E. (2012). Suppression of endothelial cell activity by inhibition of TNF- $\alpha$. Arthritis Res. Ther. 14: R88.

Sikora, M., Marczak, Ł., Kubalska, J., Graban, A., and Jakubowski, H. (2014). Identification of N-homocysteinylation sites in plasma proteins. Amino Acids 46: 235-244.

Stangl, V., Günther, C., Jarrin, A., Bramlage, P., Moobed, M., Staudt, A., Baumann, G., Stangl, K., and Felix, S.B. (2001). Homocysteine inhibits TNF- $\alpha$-induced endothelial adhesion molecule expression and monocyte adhesion via nuclear factor-кB dependent pathway. Biochem. Biophys. Res. Commun. 280: 1093-1100.

Taoufik, E., Petit, E., Divoux, D., Tseveleki, V., Mengozzi, M., Roberts, M.L., Valable, S., Ghezzi, P., Quackenbush, J., Brines, M., et al. (2008). TNF receptor I sensitizes neurons to erythropoietin- and VEGF-mediated neuroprotection after ischemic and excitotoxic injury. Proc. Natl. Acad. Sci. U. S. A. 105: 6185-6190. 
Ushio-Fukai, M. (2006). Redox signaling in angiogenesis: role of NADPH oxidase. Cardiovasc. Res. 71: 226-235.

van Montfort, R.L., Congreve, M., Tisi, D., Carr, R., and Jhoti, H. 2003. Oxidation state of the active-site cysteine in protein tyrosine phosphatase 1B. Nature 423: 773-777.

Walrafen, P., Verdier, F., Kadri, Z., Chrétien, S., Lacombe, C., and Mayeux, P. (2005). Both proteasomes and lysosomes degrade the activated erythropoietin receptor. Blood 105: 600-608.

Wang, L., Chopp, M., Teng, H., Bolz, M., Francisco, M.A., Aluigi, D.M., Wang, X.L., Zhang, R.L., Chrsitensen, S., Sager, T.N., et al. (2011). Tumor necrosis factor $\alpha$ primes cerebral endothelial cells for erythropoietin-induced angiogenesis. J. Cereb. Blood Flow Metab. 31: 640-647.

Weiss, G., Ganz, T., and Goodnough, L.T. (2019). Anemia of inflammation. Blood 133: 40-50.

Wu, Y., and Zhou, B.P. (2010). TNF- $\alpha / \mathrm{NF}-\mathrm{kB} /$ Snail pathway in cancer cell migration and invasion. Br. J. Cancer 102: 639-644.
Yamagata, K., Xie, Y., Suzuki, S., and Tagami, M. (2015). Epigallocatechin-3-gallate inhibits VCAM-1 expression and apoptosis induction associated with LC 3 expressions in TNF $\alpha$ stimulated human endothelial cells. Phytomedicine 22: 431-437.

Yang, S., Wang, J., Brand, D., and Zheng, S. 2018. Role of TNF-TNF receptor 2 signal in regulatory T Cells and its therapeutic implications. Front. Immunol. 9: 784.

Zhao, T., Li, H., and Liu, Z. (2017). Tumor necrosis factor receptor 2 promotes growth of colorectal cancer via the PI3K/AKT signaling pathway. Oncol. Lett. 13: 342-346.

Zhu, M., Wang, L., Yang, J., Xie, K., Zhu, M., Liu, S., Xu, C., Wang, J., Gu, L., Ni, Z., et al. (2019). Erythropoietin ameliorates lung injury by accelerating pulmonary endothelium cell proliferation via Janus Kinase-signal transducer and activator of transcription 3 pathway after kidney ischemia and reperfusion injury. Transplant. Proc. 51: 972-978. 